\title{
Carrier Transport in High-Mobility III-V Quantum-Well Transistors and Performance Impact for High-Speed Low-Power Logic Applications
}

\author{
Gilbert Dewey, Mantu K. Hudait, Kangho Lee, Ravi Pillarisetty, Willy Rachmady, \\ Marko Radosavljevic, Titash Rakshit, and Robert Chau, Fellow, IEEE
}

\begin{abstract}
DC and high-frequency device characteristics of $\mathrm{In}_{0.7} \mathrm{Ga}_{0.3} \mathrm{As}$ and InSb quantum-well field-effect transistors (QWFETs) are measured and benchmarked against state-ofthe-art strained silicon (Si) nMOSFET devices, all measured on the same test bench. Saturation current $\left(I_{\text {on }}\right)$ gain of $20 \%$ is observed in the $\operatorname{In}_{0.7} \mathbf{G a}_{0.3} A s$ QWFET over the strained Si nMOSFET at $\left(V_{g}-V_{t}\right)=0.3 \mathrm{~V}, V_{\mathrm{ds}}=0.5 \mathrm{~V}$, and matched $I_{\text {off }}$, despite higher external resistance and large gate-to-channel thickness. To understand the gain in $I_{\text {on }}$, the effective carrier velocities $\left(\nu_{\text {eff }}\right)$ near the source-end are extracted and it is observed that at constant $\left(V_{g}-V_{t}\right)=0.3 \mathrm{~V}$ and $V_{\mathrm{ds}}=0.5 \mathrm{~V}$, the $\nu_{\text {eff }}$ of $\mathrm{In}_{0.7} \mathrm{Ga}_{0.3} \mathrm{As}$ and InSb QWFETs are 4-5 $\times$ higher than that of strained silicon $(\mathrm{Si}) \mathrm{nMOSFET}$ due to the lower effective carrier mass in the QWFETs. The product of $\nu_{\text {eff }}$ and charge density $\left(n_{s}\right)$, which is a measure of "intrinsic" device characteristics, for the QWFETs is 50\%-70\% higher than strained Si at low-voltage operation despite lower $n_{s}$ in QWFETs. Calibrated simulations of $\mathrm{In}_{0.7} \mathbf{G a}_{0.3} \mathrm{As}$ QWFETs with reduced gate-to-channel thickness and external resistance matched to the strained Si nMOSFET suggest that the higher $\nu_{\text {eff }}$ will result in more than $80 \% I_{\text {on }}$ increase over strained Si nMOSFETs at $V_{\mathrm{ds}}=0.5 \mathrm{~V},\left(V_{g}-V_{t}\right)=0.3 \mathrm{~V}$, and matched $I_{\text {off }}$, thus showing promise for future high-speed and low-power logic applications.
\end{abstract}

Index Terms-Effective carrier velocity, InGaAs, InSb, quantum-well devices, silicon, III-V materials.

\section{INTRODUCTION}

A S SILICON CMOS technology continues to scale in accordance with Moore's Law, energy efficiency becomes increasingly important. A common method of curtailing the rising power consumption that accompanies an increasing number of transistors per chip is to scale supply voltage while maintaining transistor and circuit performance. III-V compound semiconductor-based quantum-well field-effect transis-

Manuscript received January 16, 2008; revised July 16, 2008. First published September 9, 2008; current version published September 24, 2008. The review of this letter was arranged by Editor G. Meneghesso.

G. Dewey, M. K. Hudait, K. Lee, R. Pillarisetty, W. Rachmady, M. Radosavljevic, and R. Chau are with the Components Research, Technology and Manufacturing Group, Intel Corporation, Hillsboro, OR 97124 USA (e-mail: gilbert.dewey@intel.com; mantu.k.hudait@intel.com; lee290@purdue.edu; ravi.pillarisetty@intel.com; willy.rachmady@intel.com; marko.radosavljevic@intel.com; robert.s.chau@intel.com).

T. Rakshit is with the Process Technology Modeling, Technology and Manufacturing Group, Intel Corporation, Hillsboro OR 97124 USA (e-mail: titash.rakshit@intel.com).

Color versions of one or more of the figures in this letter are available online at http://ieeexplore.iee.org.

Digital Object Identifier 10.1109/LED.2008.2002945 tors (QWFETs) have been proposed as a promising device option because of high-speed switching at very low supply voltages enabled by the excellent low- and high-field electron transport properties of III-V semiconductors [1]. At supply voltages of less than $0.7 \mathrm{~V}$, III-V QWFETs have shown a significant reduction in energy-delay product compared to stateof-the-art silicon nMOSFETs [2], [3]. To quantify the powerperformance advantage of short channel III-V devices with respect to current state-of-the art strained $\mathrm{Si}$, we investigate the role of effective carrier velocity in the channel and its impact on transistor drive current.

In this letter, effective carrier velocities at the source end of $\mathrm{In}_{0.7} \mathrm{Ga}_{0.3}$ As and InSb QWFETs are extracted and benchmarked against state-of-the-art strained Si nMOSFETs. These Si devices incorporate high- $\kappa$ and metal gates [4]. DC and highfrequency device characteristics of QWFETs are also analyzed and benchmarked against the strained Si nMOSFETs all measured on the same test bench. Both measurement and simulation data are used to show the potential drive current benefits of $\mathrm{In}_{0.7} \mathrm{Ga}_{0.3}$ As QWFETs over $\mathrm{Si}$ at low-voltage operation.

\section{EFfective CARrier Velocity and Its Extraction}

Effective carrier velocity $\left(\nu_{\mathrm{eff}}\right)$ is determined from the intrinsic saturated transconductance and capacitance [5]

$$
\nu_{\text {eff }}=g_{\mathrm{mi}} /\left(W C_{\mathrm{gi}}\right)
$$

where $g_{\mathrm{mi}}$ is the saturated transconductance corrected for parasitic resistance $\left(R_{\mathrm{sd}}\right), W$ is the width of the device, and $C_{\mathrm{gi}}$ is the intrinsic gate capacitance per unit area. The value of $C_{\mathrm{gi}}$ for III-V devices cannot directly be measured since they use Schottky gates. In this letter, both $C_{\mathrm{gi}}$ and $g_{\mathrm{mi}}$ for both the $\mathrm{Si}$ and III-V devices are determined using high-frequency measurements and a small signal equivalent circuit model [6], [7]. The high-frequency response was measured from 1 to $50 \mathrm{GHz}$. Fig. 1(a) shows that the simulated $S$ parameters based on the small signal equivalent circuit model are equivalent to the measured $S$ parameters, and that the measured and extracted gate-source capacitance $\left(C_{\mathrm{gs}}\right)$ is independent of frequency. The rms error of less than $2 \%$ between measured and modeled $S$ parameters, and the frequency independent signature of small signal circuit elements allow for accurate extraction of $g_{\mathrm{mi}}$ and the total gate capacitance $\left(C_{\mathrm{gs}}+C_{\mathrm{gd}}\right)$, where $\left(C_{\mathrm{gd}}\right)$ is the gate-drain capacitance. $C_{\mathrm{gi}}$ is determined from the slope of 


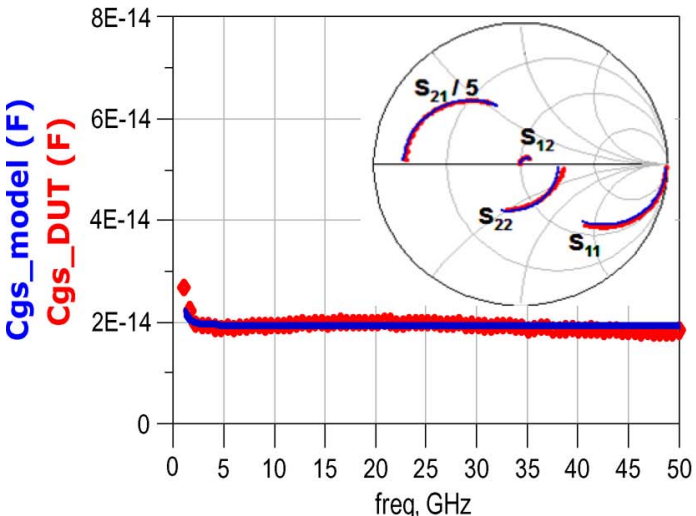

(a)

\begin{tabular}{|c|c|c|c|c|c|c|}
\hline & $V_{d s}$ & $V_{g}-V_{t}$ & $\begin{array}{c}\text { Cgi @ } \\
V_{d s}=0.05 \mathrm{~V}\end{array}$ & $n_{s}$ & $g_{m}$ & $g_{\mathrm{mi}}$ \\
\hline Material System & $\mathrm{M}$ & $\mathrm{M}$ & {$\left[\mu \mathrm{F} / \mathrm{cm}^{2}\right]$} & {$\left[\mathrm{n}_{s} / \mathrm{cm}^{\mathrm{q}}\right]$} & {$[\mu \mathrm{S} / \mathrm{\mu m}]$} & {$[\mu \mathrm{S} / \mu \mathrm{m}]$} \\
\hline $\operatorname{lnGaAs} \mathrm{T}_{\text {ins }}=8 \mathrm{~nm}$ & 0.5 & 0.3 & 0.78 & $7.9 \mathrm{E}+11$ & 1245 & 1650 \\
\hline $\operatorname{lnGaAs} \mathrm{T}_{\text {ins }}=6 \mathrm{~nm}$ & 0.5 & 0.3 & 0.94 & $9.6 \mathrm{E}+11$ & 1400 & 2190 \\
\hline $\operatorname{lnSb} \mathrm{T}_{\mathrm{ins}}=9 \mathrm{~nm}$ & 0.5 & 0.3 & 0.55 & $6.2 \mathrm{E}+11$ & 903 & 1620 \\
\hline Strained Si & 0.5 & 0.3 & 2.54 & $2.8 \mathrm{E}+12$ & 1210 & 1450 \\
\hline
\end{tabular}

(b)

Fig. 1. (a) Inset depicts simulated $S$ parameters based on the small signal equivalent circuit model compared to the measured $S$ parameters from 1 to $50 \mathrm{GHz}$. Gate to source capacitances $\left(C_{\mathrm{gs}}\right)$ simulated by the circuit model and extracted from the measured $S$ parameters of the device are shown to be independent of frequency. The rms error of less than $2 \%$ between measured and modeled $S$ parameters and the frequency independent signature of all small signal circuit elements allow for accurate extraction of $g_{\mathrm{mi}}$ and $C_{\mathrm{gi}}$. (b) Table shows the bias conditions, $C_{\mathrm{gi}}, n_{s}$ as defined by $\left(C_{\mathrm{gi}}^{*}\left(V_{g}-V_{t}\right) / \mathrm{q}\right)$, measured $g_{m}$, and $g_{\mathrm{mi}}$ of the different material systems at a constant DIBL of $150 \mathrm{mV} / \mathrm{V} \pm 5 \mathrm{mV} / \mathrm{V}$.

$\left(C_{\mathrm{gs}}+C_{\mathrm{gd}}\right) / W$ versus the various physical gate lengths of the devices. The table in Fig. 1(b) shows the bias conditions, $C_{\mathrm{gi}}$, $n_{s}$, measured $g_{m}$, and extracted $g_{\mathrm{mi}}$ of the different material systems. The larger correction from $g_{m}$ to $g_{\mathrm{mi}}$ in the III-V QWFET cases compared to the strained $\mathrm{Si}$ is due to $2-3 \times$ higher total external resistance $\left(R_{\mathrm{sd}}\right)$ in the former.

The intrinsic drive current $\left(I_{\mathrm{oni}}\right)$ is related to the effective carrier velocity $\nu_{\text {eff }}\left(x_{0}\right)$ in the channel by [8]

$$
I_{\mathrm{oni}} / W=\nu_{\mathrm{eff}}\left(x_{0}\right)^{*} C_{\mathrm{gi}}^{*}\left(V_{g}-V_{t}\right)=\nu_{\mathrm{eff}}\left(x_{0}\right)^{*} n_{s}
$$

where $x_{0}$ corresponds to the conduction band peak at the source side of the channel, $V_{t}$ is the transistor threshold voltage using the standard linear peak transconductance extraction method, and $n_{s}$ is channel charge density at the source end. Because full $C_{g}-V_{g}$ curves are not available for III-V QWFETs, $n_{s}$ is approximated using $\left(C_{\mathrm{gi}}^{*}\left(V_{g}-V_{t}\right) / \mathrm{q}\right)$, where $C_{\mathrm{gi}}$ is the channel capacitance at $\mathrm{Vds}=0.05 \mathrm{~V}$. The $\nu_{\text {eff }}$ determined from the intrinsic transconductance method as defined in (1) can be used as an approximation of $\nu_{\text {eff }}\left(x_{0}\right)$ with the understanding that $\nu_{\text {eff }}\left(x_{0}\right)$ may be overestimated by $15 \%-30 \%$ [8].

\section{DEVICES}

The InSb and $\operatorname{In}_{0.7} \mathrm{Ga}_{0.3}$ As quantum-well transistors were fabricated using standard processing techniques [1], [3]. For the InSb QWFETs, the InSb quantum well is $20 \mathrm{~nm}$ thick with a room-temperature Hall mobility of $20000-30000 \mathrm{~cm}^{2}$. $\mathrm{V}^{-1} \cdot \mathrm{s}^{-1}$ at a sheet carrier density of $1.3 \times 10^{12} \mathrm{~cm}^{-2}$. The physical gate insulator thickness $\left(T_{\mathrm{ins}}\right)$, which is the wide bandgap semiconductor thickness between the Schottky gate and the quantum well of the device, is $\sim 9 \mathrm{~nm}$. For the two $\operatorname{In}_{0.7} \mathrm{Ga}_{0.3} \mathrm{As}$ QWFET cases, the physical gate insulator thickness is $\sim 6$ and $\sim 8 \mathrm{~nm}$. The quantum well is $13 \mathrm{~nm}$ thick with a roomtemperature Hall mobility of $10000 \mathrm{~cm}^{2} \cdot \mathrm{V}^{-1} \cdot \mathrm{s}^{-1}$ at a sheet carrier density of $3.5 \times 10^{12} \mathrm{~cm}^{-2}$. The physical gate length of the $\mathrm{InSb}$ and $\mathrm{In}_{0.7} \mathrm{Ga}_{0.3}$ As QWFETs ranges from 60 to $200 \mathrm{~nm}$. The strained Si nMOSFET devices have thin gate oxide and physical gate lengths ranging from 30 to $60 \mathrm{~nm}$.

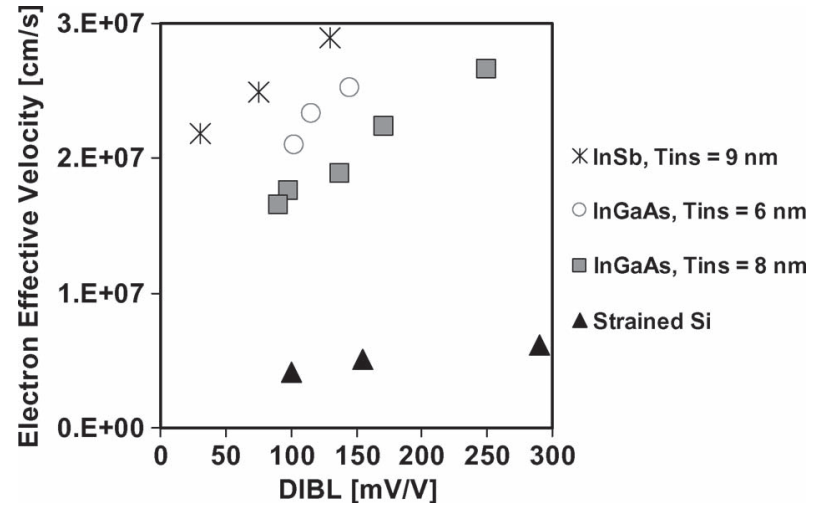

Fig. 2. Effective electron velocity versus DIBL for $\operatorname{In}_{0.7} \mathrm{Ga}_{0.3}$ As with $T_{\text {ins }}$ of 6 and $8 \mathrm{~nm}$, InSb with $T_{\text {ins }}$ of $9 \mathrm{~nm}$ and strained Si nMOSFET at $V_{\mathrm{ds}}=0.5 \mathrm{~V}$ and a gate overdrive of $\left(V_{g}-V_{t}\right)=0.3 \mathrm{~V}$. At a constant DIBL of $150 \mathrm{mV} / \mathrm{V}$, $\mathrm{In}_{0.7} \mathrm{Ga}_{0.3} \mathrm{As}(8 \mathrm{~nm}), \mathrm{In}_{0.7} \mathrm{Ga}_{0.3} \mathrm{As}(6 \mathrm{~nm})$, and $\mathrm{InSb}(9 \mathrm{~nm})$ show $3.7 \times, 4.1 \times$, and $5 \times$ increase in $\nu_{\text {eff }}$ over strained $\mathrm{Si}$, respectively.

\section{RESULTS AND DISCUSSION}

The effective carrier velocities of the various devices are shown versus DIBL in Fig. 2. At a constant DIBL of $\sim 150 \mathrm{mV} / \mathrm{V}$, the $8-\mathrm{nm} \quad T_{\mathrm{ins}} \quad \mathrm{In}_{0.7} \mathrm{Ga}_{0.3} \mathrm{As}$, the 6-nm $T_{\text {ins }} \operatorname{In}_{0.7} \mathrm{Ga}_{0.3} \mathrm{As}$, and the 9-nm $T_{\text {ins }}$ InSb QWFETs show $3.7 \times, 4.1 \times$, and $5 \times$ increase in $\nu_{\text {eff }}$, respectively, over that of the strained Si nMOSFET. This increase in $\nu_{\text {eff }}$ occurs despite a reduction in charge density $\left(n_{s}\right)$ in the $\mathrm{In}_{0.7} \mathrm{Ga}_{0.3} \mathrm{As}$ and InSb QWFETs compared to the Si nMOSFET. As the gate insulator thickness is scaled for $\operatorname{In}_{0.7} \mathrm{Ga}_{0.3}$ As QWFETs from 8 to $6 \mathrm{~nm}$, the effective velocity increases by $20 \%$ at a constant DIBL and at a constant $I_{\text {off }}$ due to the combination of gate length and insulator thickness scaling. Because both $\nu_{\text {eff }}$ and charge density increase in the QWFET devices with insulator scaling, significant increase in device performance is expected with continued $T_{\text {ins }}$ reduction.

In Fig. 3(a), the $\nu_{\text {eff }}^{*} n_{s}$ product, which is proportional to intrinsic $I_{\mathrm{oni}}$, is shown versus gate overdrive $\left(V_{g}-V_{t}\right)$ of (1) the 6-nm $T_{\mathrm{ins}} \mathrm{In}_{0.7} \mathrm{Ga}_{0.3}$ As QWFET and (2) the strained $\mathrm{Si}$ nMOSFET at matched $I_{\text {off }}$ and DIBL. For low-voltage operation targeted at $V_{\mathrm{ds}}=V_{\mathrm{gs}}=0.5 \mathrm{~V}$ and an ideal $V_{t}$ of $\sim 0.2 \mathrm{~V}$ 


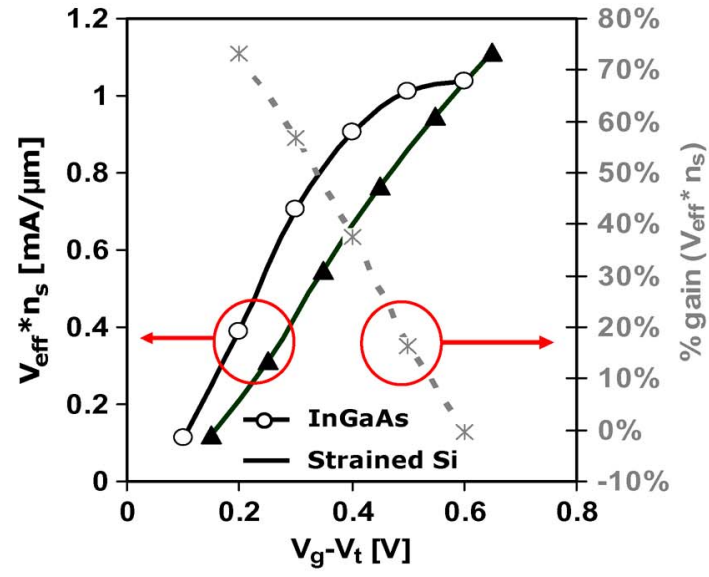

(a)

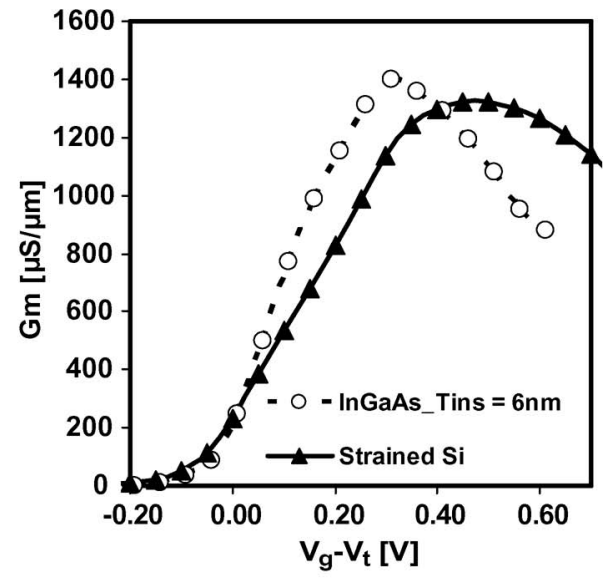

(b)

Fig. 3. (a) Primary $y$-axis depicts the $v_{\text {eff }}^{*} n_{s}$ product and the (right) secondary $y$-axis shows the percentage gain in $I_{\text {on }}$ of the $\mathrm{In}_{0.7} \mathrm{Ga}_{0.3} \mathrm{As}_{\mathrm{OWFET}}$ $\left(T_{\mathrm{ins}}=6 \mathrm{~nm}\right)$ over that of the strained $\mathrm{Si}$ nMOSFET versus gate overdrive $\left(V_{g}-V_{t}\right)$. (b) Measured transconductance of $\mathrm{In}_{0.7} \mathrm{Ga}_{0.3} \mathrm{As}_{\mathrm{QWFET}} \mathrm{Qnd}_{\mathrm{B}}$ strained Si nMOSFET versus gate overdrive. In both Fig. $3(\mathrm{a})$ and (b), DIBL is $\sim 150 \mathrm{mV} / \mathrm{V}, I_{\mathrm{off}}$ is equivalent, and $V_{\mathrm{ds}}=0.5 \mathrm{~V}$ for both material systems.

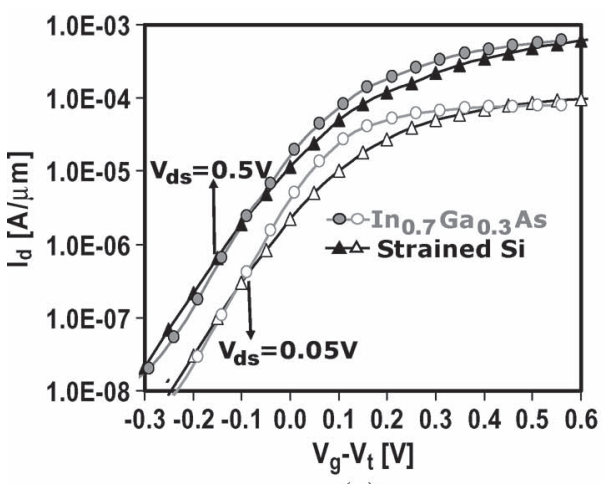

(a)

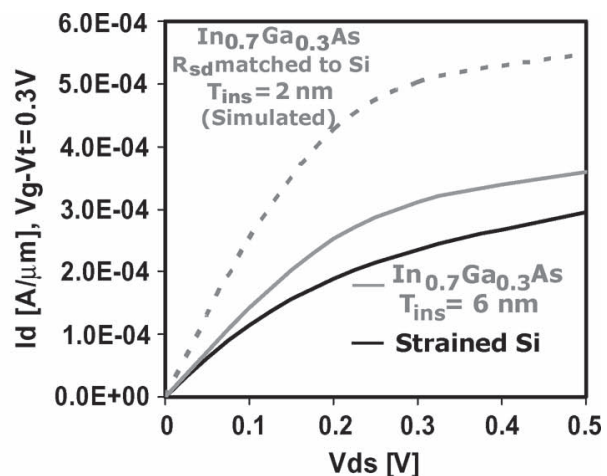

(b)

Fig. 4. (a) $I_{d}-\left(V_{g}-V_{t}\right)$ for 80-nm $L_{g} \operatorname{In}_{0.7} \mathrm{Ga}_{0.3}$ As $\left(T_{\mathrm{ins}}=6 \mathrm{~nm}\right)$ quantum-well transistor and 40-nm $L_{g}$ strained Si nMOSFET at matched $I_{\text {off }}$ with $V_{\mathrm{ds}}=0.5 \mathrm{~V}$ and $0.05 \mathrm{~V}$. DIBL for both devices is matched at $150 \mathrm{mV} / \mathrm{V}( \pm 5 \mathrm{mV} / \mathrm{V})$ and subthreshold slope is matched at $90 \mathrm{mV} / \mathrm{decade}( \pm 3 \mathrm{mV} / \mathrm{decade})$. (b) $I_{d}-V_{\mathrm{ds}}$ for $80-\mathrm{nm} L_{g} \mathrm{In}_{0.7} \mathrm{Ga}_{0.3} \mathrm{As}\left(T_{\mathrm{ins}}=6 \mathrm{~nm}\right)$ QWFET and 40-nm $L_{g}$ strained Si nMOSFET with matched $I_{\text {off }}$ and DIBL of $\sim 150 \mathrm{mV} / \mathrm{V}$. The dotted line represents simulated $\operatorname{In}_{0.7} \mathrm{Ga}_{0.3}$ As data with external resistance $\left(R_{\mathrm{sd}}\right)$ matched to that of the strained $\mathrm{Si}$ and gate-to-channel separation $\left(T_{\mathrm{ins}}\right)$ scaled to $2 \mathrm{~nm}$.

for logic applications, the resulting gate overdrive is $\sim 0.3 \mathrm{~V}$. At $\mathrm{Vg}-\mathrm{Vt}=0.3 \mathrm{~V}$, the $\mathrm{In}_{0.7} \mathrm{Ga}_{0.3}$ As QWFET shows a $\sim 55 \%$ gain in $I_{\text {oni }}$ over the strained Si nMOSFET [Fig. 3(a)]. This demonstrates that despite lower $n_{s}$, III-V QWFETs can exhibit higher $I_{\mathrm{on}}$ than strained $\mathrm{Si}$ due to higher $\nu_{\text {eff }}$. In addition, Fig. 3(b) shows that $g_{m}$ of the $\mathrm{In}_{0.7} \mathrm{Ga}_{0.3}$ As QWFET peaks at a lower $\left(V_{g}-V_{t}\right)$ value compared to that of the strained $\mathrm{Si}$ nMOSFET. This indicates that III-V QWFETs have a performance advantage over strained $\mathrm{Si}$ at low-voltage operation.

Finally, the room temperature transfer and output characteristics obtained for the 80-nm physical gate length $\operatorname{In}_{0.7} \mathrm{Ga}_{0.3} \mathrm{As}$ QWFET $\left(T_{\mathrm{ins}}=6 \mathrm{~nm}\right)$ and the 40-nm physical gate length strained Si nMOSFET are shown in Fig. 4(a) and (b), respectively. Because the Si device has a $V_{t}$ of $0.36 \mathrm{~V}$ and the $\mathrm{In}_{0.7} \mathrm{Ga}_{0.3} \mathrm{As}$ has a $V_{t}$ of $0.1 \mathrm{~V}$, the transfer characteristics are shown versus $V_{g}-V_{t}$. $V_{t}$ is calculated in all cases using the standard linear peak transconductance extraction method. In Fig. 4(a) and (b), DIBL and subthreshold slope of the $\mathrm{In}_{0.7} \mathrm{Ga}_{0.3}$ As and Si devices are matched at $\sim 150 \mathrm{mV} / \mathrm{V}$ and $\sim 90 \mathrm{mV} / \mathrm{dec}$, respectively. At $V_{\mathrm{ds}}=0.5 \mathrm{~V}$ and $V_{g}-V_{t}=$ $0.3 \mathrm{~V}, I_{\mathrm{on}}$ for the $\mathrm{In}_{0.7} \mathrm{Ga}_{0.3}$ As and $\mathrm{Si}$ devices is 0.36 and
$0.29 \mathrm{~mA} / \mu \mathrm{m}$, respectively. This occurs despite the fact that with current processing conditions, $\mathrm{In}_{0.7} \mathrm{Ga}_{0.3}$ As devices exhibit a thicker gate-to-channel separation and $\sim 2 \times$ higher external resistance $\left(R_{\mathrm{sd}}\right)$ than the Si nMOSFETs. To further examine performance benefits, simulation based on a coupled 2-D Poisson and a single effective mass-based nonequilibrium Green's function method [9], [10] was first calibrated to the $\mathrm{In}_{0.7} \mathrm{Ga}_{0.3}$ As QWFET data. Next, with $R_{\mathrm{sd}}$ matched to strained $\mathrm{Si}$ and $T_{\text {ins }}$ scaled down to $2 \mathrm{~nm}$, the simulation projects that the $\mathrm{In}_{0.7} \mathrm{Ga}_{0.3}$ As QWFET can exhibit $>80 \%$ improvement in $I_{\text {on }}$ over the Si device at equivalent $I_{\text {off }}$ as shown in Fig. 4(a).

\section{CONCLUSION}

The effective carrier velocities for $\mathrm{InSb}$ and $\mathrm{In}_{0.7} \mathrm{Ga}_{0.3} \mathrm{As}$ QWFETs, and state-of-the-art strained Si nMOSFET devices are extracted using an intrinsic transconductance method. It is observed that despite lower charge density, the effective carrier velocities of the high-mobility $\mathrm{In}_{0.7} \mathrm{Ga}_{0.3}$ As and InSb QWFETs exhibit a $4.1 \times$ and $5 \times$ increase, respectively, over that of strained Si nMOSFETs at a constant DIBL. The increase in $\nu_{\text {eff }}$ 
in the $\mathrm{In}_{0.7} \mathrm{Ga}_{0.3}$ As QWFET translates to $20 \%$ improvement in $I_{\text {on }}$ over the strained Si nMOSFET at matched DIBL, $I_{\text {off }}$, $\left(V_{g}-V_{t}\right)=0.3 \mathrm{~V}$, and at $V_{\mathrm{ds}}=0.5 \mathrm{~V}$, despite a thick $T_{\mathrm{ins}}$ and $\sim 2 \times$ higher $R_{\mathrm{sd}}$. At $R_{\mathrm{sd}}$ matched to strained $\mathrm{Si}$ and $T_{\mathrm{ins}}$ scaled to $2 \mathrm{~nm}$, it is possible for the $\mathrm{In}_{0.7} \mathrm{Ga}_{0.3}$ As QWFET to exhibit $>80 \% I_{\text {on }}$ increase over the strained Si nMOSFET, making the III-V QWFET a promising candidate for future high-speed and ultralow-power logic applications.

\section{REFERENCES}

[1] S. Datta, T. Ashley, J. Brask, L. Buckle, M. Doczy, M. Emeny, D. Hayes, K. Hilton, R. Jefferies, T. Martin, T. J. Phillips, D. Wallis, P. Wilding, and R. Chau, " $85 \mathrm{~nm}$ gate length enhancement and depletion mode InSb quantum well transistors for ultra high speed and very low power digital logic applications," in IEDM Tech. Dig., 2005, pp. 763-766.

[2] D. H. Kim, J. A. del Alamo, J. H. Lee, and K. S. Seo, "Performance evaluation of $50 \mathrm{~nm} \mathrm{In}_{0.7} \mathrm{Ga}_{0.3}$ As HEMTs for beyond-CMOS logic applications," in IEDM Tech. Dig., 2005, pp. 767-770.

[3] M. K. Hudait, G. Dewey, S. Datta, J. M. Fastenau, J. Kavalieros, W. K. Liu, D. Lubyshev, R. Pillarisetty, W. Rachmady, M. Racosavljevic, T. Rakshit, and R. Chau, "Heterogeneous integration of enhancement mode $\operatorname{In}_{0.7} \mathrm{Ga}_{0.3}$ As quantum well transistor on silicon substrate usin thin $(\leq 2 \mu \mathrm{m})$ composite buffer architecture for high-speed and low-voltage (0.5 V) logic applications," in IEDM Tech. Dig., 2007, pp. 625-628.

[4] R. Chau, S. Datta, M. Doczy, B. Doyle, J. Kavalieros, and M. Metz, "High- $\kappa /$ metal-gate stack and its MOSFET characteristics," IEEE Electron Device Lett., vol. 25, no. 6, pp. 408-410, Jun. 2004.

[5] A. Lochtefeld, I. J. Djomehri, G. Samudra, and D. A. Antoniadis, "New insights into carrier transport in n-MOSFETs," IBM J. Res. Develop., vol. 46, no. 2/3, pp. 347-357, May 2002.

[6] Y. L. Lai and C. T. Chen, "A novel cold-FET method for determining extrinsic capacitances using a capacitive transmission line model," in Proc. IEEE MTT-S Dig., 2001, pp. 1261-1264.

[7] P. M. White and R. M. Healy, "Improved equivalent circuit for determination of MESFET and HEMT parasitic capacitances from 'Coldfet' measurements," IEEE Microw. Guided Wave Lett., vol. 3, no. 12, pp. $453-$ 454, Dec. 1993.

[8] A. Lochtefeld and D. A. Antoniadis, "On experimental determination of carrier velocity in deeply scaled NMOS: How close to the thermal limit?" IEEE Electron Device Lett., vol. 22, no. 2, pp. 95-97, Feb. 2001.

[9] R. Lake and S. Datta, "Nonequilibrium Green's-function method applied to double-barrier resonant-tunneling diodes," Phys. Rev. B, Condens. Matter, vol. 45, no. 12, pp. 6670-6685, Mar. 1992.

[10] S. Datta, Quantum Transport: Atom to Transistor. Cambridge, U.K.: Cambridge Univ. Press, 2005. 